\title{
TV Viewing by Children During Times of Conflict ${ }^{1}$
}

Millie Ferrer ${ }^{2}$

Amid tragic times of war and terrorism, people naturally want to keep current. However, without realizing it, many families can spend too many hours watching TV. The continuous bombardment of the latest accounts of what is happening in the world can add to children's fear, confusion, and stress. Experts agree that viewing a lot of violence in the media can be unhealthy for children. Parents need to limit the amount of television coverage their children watch. It is especially important to limit young children's exposure to graphic images. No matter what age, each person interprets programs and messages differently. Children in particular can easily misinterpret what is going on, thereby increasing their sense of fear.

If children are going to watch programs about conflict, limit their amount of viewing. Watch with them for a brief time, and then turn the set off. Afterwards, encourage them to talk about their reactions to what they saw. By listening carefully and respecting their concerns, you can assure them that they can talk about anything with you. If you need to clarify some of the news, keep your explanations appropriate to the children's development.

Following are some tips to assist you in talking with children about these events:

- Young Children - Young children have limited ability to distinguish fact from fantasy. They can be confused about the degree of danger they personally face. It is never easy to know what to say to young children in times like these. However, it is important to listen to them and acknowledge their feelings.

Respond to your child's questions and concerns in a supportive and sensitive way. Do not overload young children with too much information. Instead, focus on reassuring your child that you will try your very best to make sure $\mathrm{s} / \mathrm{he}$ is safe. Because of young children's limited language ability, they may benefit from drawing pictures about what they are thinking and feeling. To gain insight into your child's thoughts, ask him or her to tell you about their picture.

- Older Children - Older children know the difference between fantasy and reality, but they lack perspective. Take time to watch the news with your child and talk about what $\mathrm{s} /$ he sees and hears. Your child is likely to state opinions or ask questions about these events. Provide lots of time for questions. Asking the same question over and

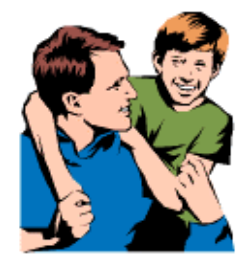
over again may be your child's way of asking for reassurance. Acknowledge your child's feelings and clarify any concerns s/he may have.

1. This document is FCS9191, one of a series of the Department of Family, Youth and Community Sciences, Florida Cooperative Extension Service, IFAS, University of Florida, Gainesville FL 32611: First published: May 2003. Reviewed by Elizabeth Bolton, Ph.D., Department of Family, Youth and Community Sciences. Please visit the EDIS Web site at http://edis.ifas.ufl.edu

2. Millie Ferrer, Ph.D., professor, Department of Family, Youth and Community Sciences, University of Florida, Gainesville FL 32611. 
It is important to realize that kids of all ages may feel fearful. Do not assume your child can handle these feelings alone. Older children also are concerned about fairness and care about what happens to others. They may want to help out. Your child may want to write letters or say prayers for the victims and their families or for military personnel. Perhaps your family can contribute clothing, money, or supplies through the many disaster relief organizations.
In the wake of current events, it is important to remember that parents play an essential role in helping their children feel safe and secure. You may want to model calm and control. Stay close to your children and try to keep as normal a routine as possible. 